\title{
Transcriptome-based screening of intracellular pathways and angiogenesis related genes at different stages of thiram induced tibial lesions in broiler chickens
}

Ali Raza Jahejo ${ }^{1}$, Ding Zhang ${ }^{1}$, Sheng Niu', Raza Ali Mangi', Afrasyab Khan ${ }^{1}$, Muhammad Farhan Qadir ${ }^{1}$ Ajab Khan ${ }^{1}$, Huan-chun Chen ${ }^{2}$ and Wen-xia $\operatorname{Tian}^{1 *}$ (i)

\begin{abstract}
Background: The Tibial dyschondroplasia (TD) in fast-growing chickens is mainly caused by improper blood circulation. The exact mechanism underlying angiogenesis and vascularization in tibial growth plate of broiler chickens remains unclear. Therefore, this research attempts to study genes involved in the regulation of angiogenesis in chicken red blood cells. Twenty-four broiler chickens were allotted into a control and thiram (Tetramethyl thiuram disulfide) group. Blood samples were collected on day 2, 6 (8- and 14-days old chickens) and 15 (23 days old chickens).

Results: Histopathology and hematoxylin and eosin (H\&E) results showed that angiogenesis decreased on the 6th day of the experiment but started to recover on the 15th day of the experiment. Immunohistochemistry (IHC) results confirmed the expressions of integrin alpha-v precursor (ITGAV) and clusterin precursor (CLU). Transcriptome sequencing analysis evaluated 293 differentially expressed genes (DEGs), of which 103 up-regulated genes and 190 down-regulated genes were enriched in the pathways of neuroactive ligand receptor interaction, mitogen-activated protein kinase (MAPK), ribosome, regulation of actin cytoskeleton, focal adhesion, natural killer cell mediated cytotoxicity and the notch signalling pathways. DEGs $(n=20)$ related to angiogenesis of chicken erythrocytes in the enriched pathways were thromboxane A2 receptor (TBXA2R), interleukin-1 receptor type 1 precursor (IL1R1), ribosomal protein L17 (RPL17), integrin beta-3 precursor (ITGB3), ITGAV, integrin beta-2 precursor (ITGB2), ras-related C3 botulinum toxin substrate 2 (RAC2), integrin alpha-2 (ITGA2), IQ motif containing GTPase activating protein 2 (IQGAP2), ARF GTPase-activating protein (GIT1), proto-oncogene vav (VAV1), integrin alpha-llb-like (ITGA5), ras-related protein Rap-1b precursor (RAP1B), tyrosine protein kinase Fyn-like (FYM), tyrosine-protein phosphatase non-receptor type 11 (PTPN11), protein patched homolog 1 (PTCH1), nuclear receptor corepressor 2 (NCOR2) and mastermind like protein 3 (MAML3) selected for further confirmation with qPCR. However, commonly DEGs were sarcoplasmic/ endoplasmic reticulum calcium ATPase 3 (ATP2A3), ubiquitin-conjugating enzyme E2 R2 (UBE2R2), centriole cilia and spindle-associated protein (CCSAP), coagulation factor XIII A chain protein (F13A1), shroom 2 isoform X6 (SHROOM2), ras GTPase-activating protein 3 (RASA3) and CLU.
\end{abstract}

Conclusion: We have found potential therapeutic genes concerned to erythrocytes and blood regulation, which regulated the angiogenesis in thiram induced TD chickens. This study also revealed the potential functions of erythrocytes.

Keywords: Angiogenesis, Broiler, Chondrocytes, Erythrocytes, Thiram

\footnotetext{
* Correspondence: wenxiatian@126.com

${ }^{1}$ College of Animal Science and Veterinary Medicine, Shanxi Agricultural

University, Taigu 030801, China

Full list of author information is available at the end of the article
}

(c) The Author(s). 2020 Open Access This article is distributed under the terms of the Creative Commons Attribution 4.0 International License (http://creativecommons.org/licenses/by/4.0/), which permits unrestricted use, distribution, and reproduction in any medium, provided you give appropriate credit to the original author(s) and the source, provide a link to the Creative Commons license, and indicate if changes were made. The Creative Commons Public Domain Dedication waiver (http://creativecommons.org/publicdomain/zero/1.0/) applies to the data made available in this article, unless otherwise stated. 


\section{Background}

Tibial dyschondroplasia (TD) is a bone deformity disease characterized by accumulation of non-mineral and avascular cartilage that causes chondrocyte death due to lack of blood supply [1, 2]. The death of blood vessels membrane is called angionecrosis, which reduces angiogenesis in broilers and causes TD [3]. It has been reported that high level of blood vessels formation increase the size of the growth plate and reduce the chance of TD [4]. Thiram is a pesticide that is commonly used in agriculture. It may cause lameness and cartilage defect in avian [2,5]. Previous studies have demonstrated that thiram induces proliferation and disturbs the endochondral calcification in the growth plate of broiler chickens [6]. However, it is also reported that red blood cells have a direct role in the immune response and have an indirect effect on certain pathogens and pro-inflammatory factors [7, 8]. A study also showed that tibial angiogenesis in the hypertrophic zone was strongly suppressed by thiram-induced TD [9]. These clues suggest that the development of TD may be related to the immune response of red blood cells in chicken blood vessels. Previously, we reported that the transcripts of eight avian $\beta$-defensins (AvBDs) and liverexpressed antimicrobial peptide 2 (LEAP-2) found in chicken erythrocytes participated in Mareks disease virus (MDV) induced host immune response [10]. Erythrocytes also play a vital role in the immune response to TD chickens by upregulating the host defense peptides (HDPs) [11]. These findings raise the possibility that immune responses of chicken erythrocytes contribute to prevent and treat TD. Whereas, the angionecrosis has been proved to be the cause of thiram induced TD and most of the literature confirms the detrimental effects of angiogenesis [2-4]. However, the mechanisms underlying the angionecrosis leading to TD has not been well studied. Therefore, the current study of transcriptome sequencing investigated the potential target genes of angiogenesis in chicken erythrocytes of thiram induced TD. These genes regulate blood circulation and angiogenesis, providing a new insight into the therapeutic manipulation in order to prevent TD.

\section{Results}

\section{Histopathology}

The chickens $(n=4)$ in a control group were active, and healthy. However, the chickens $(n=4)$ in thiram group had lesions in tibiotarsus bone. The lameness began on day 2 , became more visible on day 6 , and decreased on day 15 . More lesions and few blood vessels were seen in the growth plate of thiram-fed chickens on day 2 . The lesions were severed on day 6 and relatively decreased on day 15 (Fig. 1a). The differences within the groups turned out to be more prominent and obvious, because the blood vessels began to recover in the thiram group on day 15 as compared to day 6 , when some area of the growth plate had been calcified and vascularized after the severity of lesions.

The histological examination of the hypertrophic zone of the growth plate was observed under a microscope. The chondrocytes were in a columnar arrangement, and the blood vessels in the control group were normal. The proliferation of chondrocytes was affected, as their size and shape were degraded. These arrangements were less disordered on day 2 , more on day 6 , and began to recover on day 15 in thiram group. Most importantly, the erythrocytes could be clearly seen in and around the chondrocytes of the control and thiram groups (Fig. 1b).

Denser erythrocytes were found on day 2, lighter on day 6 , and prominent recovery was seen on day 15 (Additional file 4: Figure S1). However, the quantification of microscopic figures with ImageJ software suggests that the area and the density of blood vessels started improving on day 15, (Additional file 4: Figure S2 A and B).

Expression of CLU and ITGAV in chicken red blood cells was examined by IHC analysis (Fig. 1c). The quantification results by ImageJ software with IHC profile suggest that as compared to the control group, expression of CLU was increased in the thiram group on day 2 (Additional file 4: Figure S3 A, S2 C). Whereas the expression of ITGAV appeared less in number in thiram group as compared to the control group on day 15 (Additional file 4: Figure S3 B, S2 C).

\section{Differentially expressed genes}

The analysis of differentially expressed genes $(n=3)$ on day 2, 6 and 15 revealed that 293 genes were differentially expressed $(P<0.05)$. The number of differentially expressed genes on day 2, 6 and 15 were 49 (39 ${ }^{\uparrow}$ up, $10^{\downarrow}$ down), 80 (49 $9^{\uparrow}$ up, $31^{\downarrow}$ down), and 164 (15 $5^{\uparrow}$ up, $149^{\downarrow}$ down), respectively (Fig. 2a. Additional file 1). Hierarchical cluster analysis also showed that chickens on day 6, 2 and 15 formed more gene expression patterns, respectively. The gene expression patterns could be seen similar on day 2 and 6 (Fig. 2b).

We selected some potential genes which were expressed commonly in the groups. The commonly observed gene $U B E 2 R 2$ was downregulated on day 2 and upregulated on day 6. Other genes such as, ATP2A3, F13A1, SHROOM2, $R A S A 3$ and $C L U$ were upregulated on day 2 and downregulated on day 15 . The only gene upregulated on both 2 and 15 days was CCSAP (Additional file 2: Table S1).

\section{GO annotations}

On days 2, 6 and 15, a total of 49, 80 and 164 DEGs were respectively assigned to the gene ontology (GO). GO enrichment analysis was performed from three aspects of cellular component, molecular function and biological process. Among these categories, most DEGs were enriched in the cellular component category. Within the 

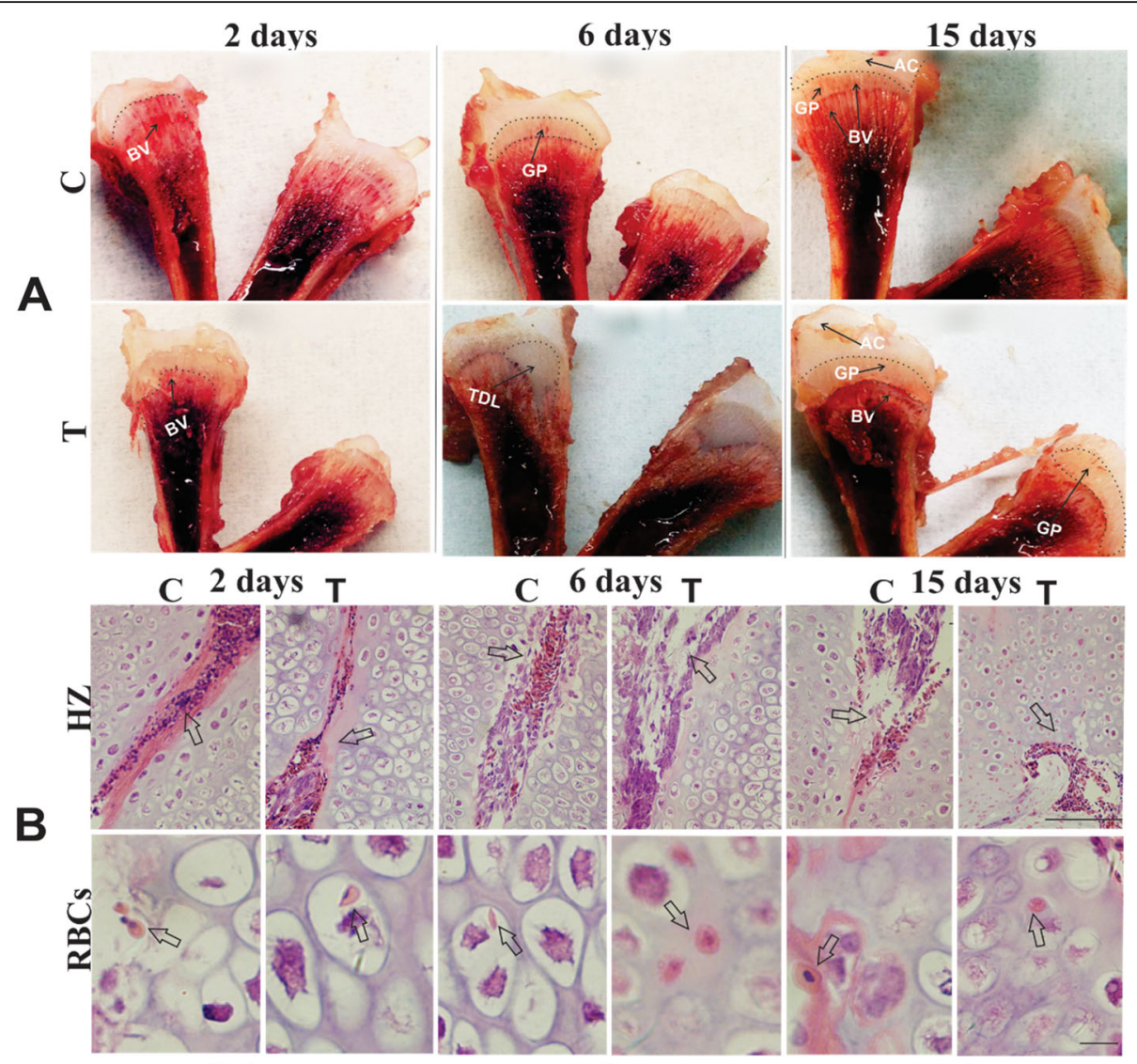

C 15 days $T$
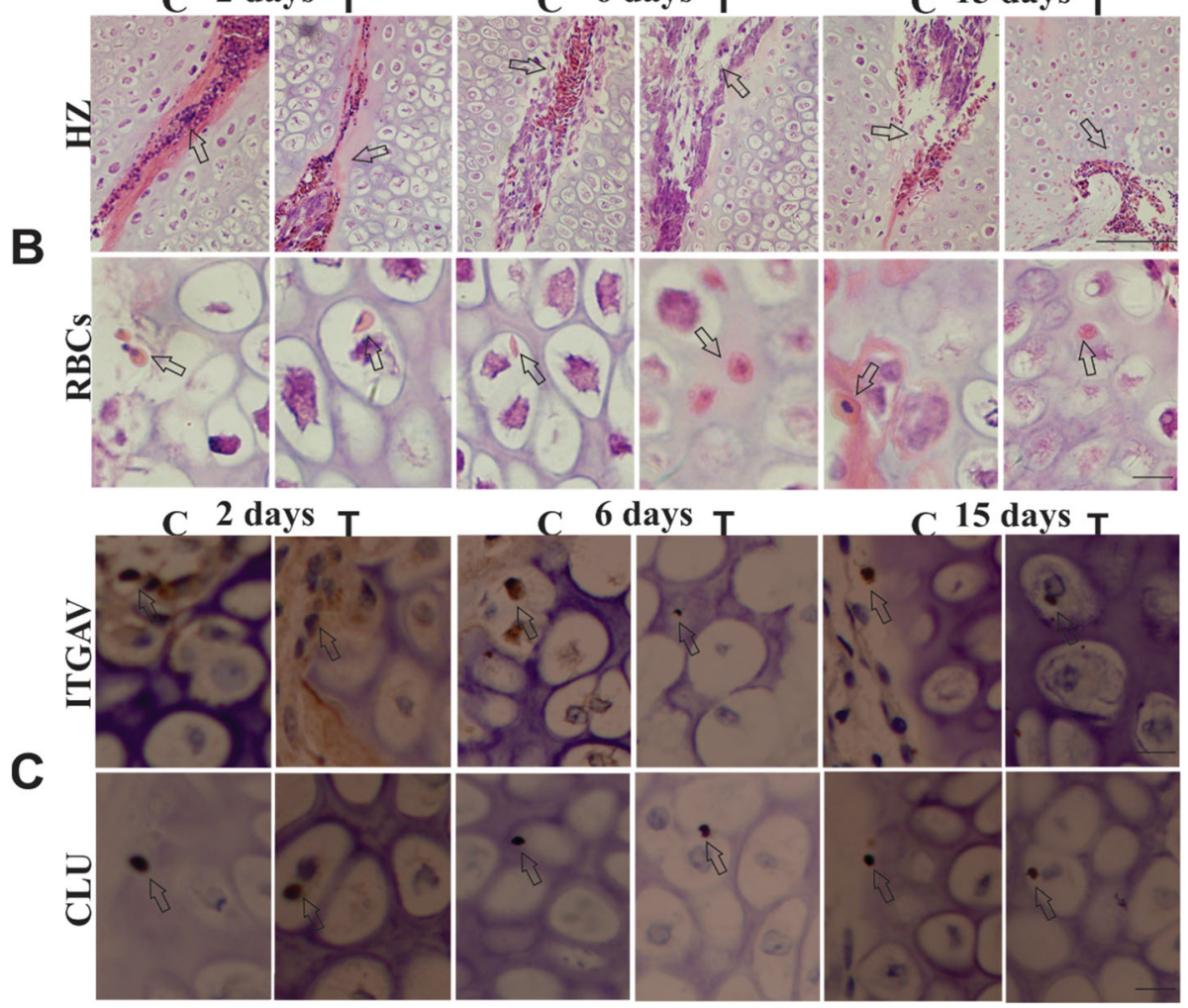

Fig. 1 Morphology, histology and immunohistochemistry $(n=4)$. a The morphological observation of tibia, on lesion development and blood vessel distribution in the tibiotarsus of chicken. $\mathrm{AC}=$ articular cartilage; $\mathrm{GP}=$ growth plate; $\mathrm{BV}=$ blood vessels; $\mathrm{TDL}=$ tibial dyschondroplasia lesions. b H\&E stained histopathology of the tibial growth plate (GP). The chondrocytes were organized, and growth plate shows regular columns of cells surrounded by blood vessels in the hypertrophic zone of the control group and reduced number of blood vessels in the thiram group (Day 2, 6 and 15). The chondrocytes were damaged, and necrosis was observed. Most importantly erythrocytes were seen in the chondrocytes of control and thiram-fed chickens. Arrows in $\mathrm{HZ}$ indicate the blood vessels. $\mathrm{HZ}=$ hypertrophic zone (Bar-100 $\mu \mathrm{m})$. Arrows in RBCs shows the red blood cells which were seen within/around chondrocytes. RBCs = red blood cells (Bar-50 $\mu \mathrm{m}$ ), $C=$ control, $T=$ thiram. $\mathbf{c}$ Immunohistochemical localization of ITGAV and CLU in control and thiram groups. The control group on day 15 has more localization of ITGAV than thiram group. The thiram group on day 15 has higher localization of CLU which decreased on day 15 in the control group. Arrows indicate the expression of ITGAV and $\mathrm{CLU}$ in red blood cells which were seen within/around chondrocytes. $\mathrm{T}=$ thiram, $\mathrm{C}=$ control. (Bar-50 $\mu \mathrm{m})$

cellular component category, cell and cell part were the most dominant subcategories. Regarding the molecular function category, the four most abundant sub-categories were binding, catalytic activity, molecular transducer activity, and transporter activity. As for the biological process category, the most DEGs were assigned to a cellular process, single organism process, biological regulation, and metabolic process (Fig. 3). 

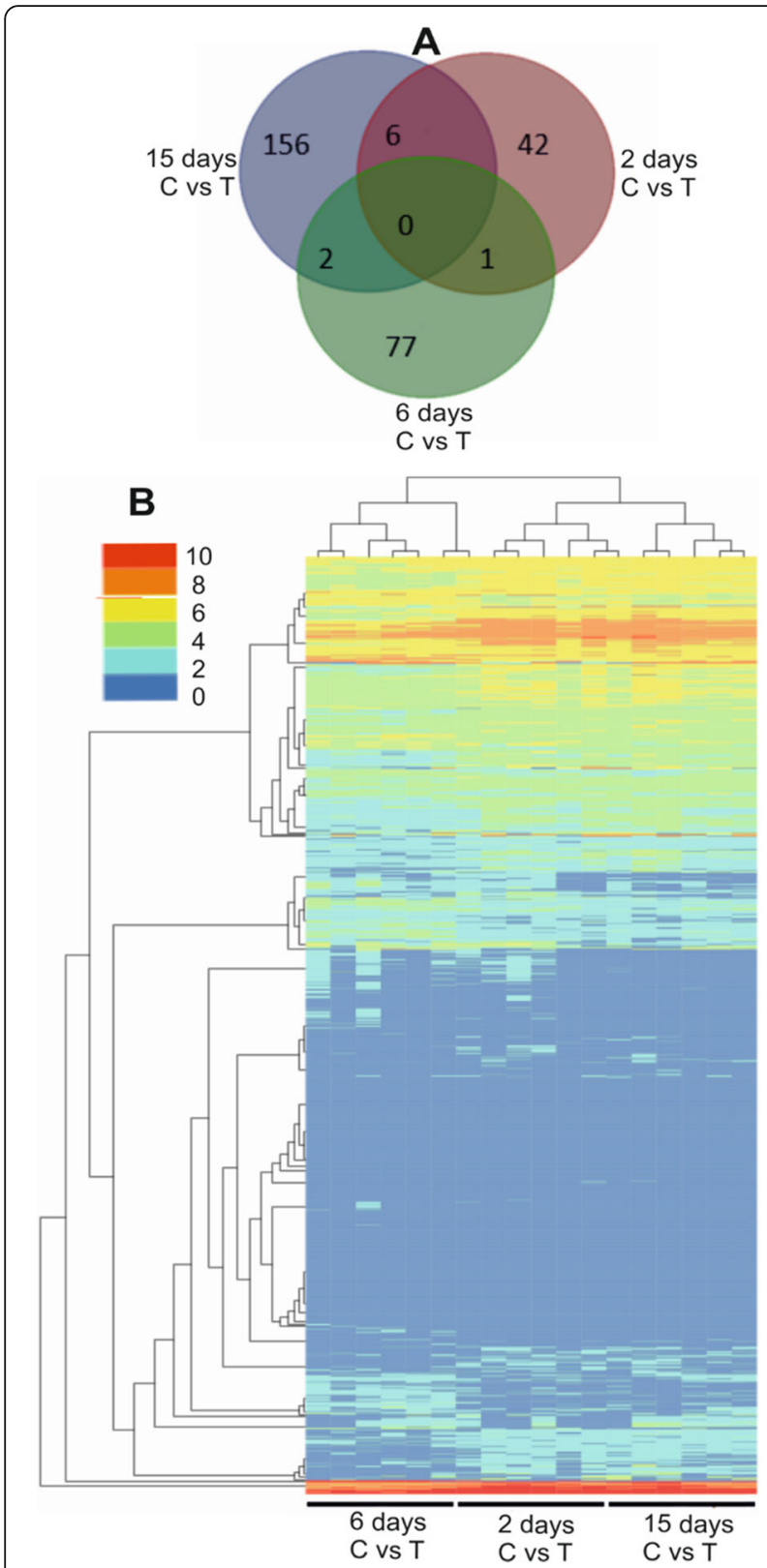

Fig. 2 Differential expression of genes $(n=3)$. a Analysis of DEGs, using Venn diagrams. There were 49, 80 and 164 DEGs identified on day 2, 6 and 15 respectively. Only a single gene expressed commonly, on day 2 and 6 . Total 6 genes were expressed commonly on day 2 and 15 . Whereas the total number of genes expressed commonly on day 6 and 15 were 2 . b Hierarchical clustering analyses of 49,80 and 164 transcripts on day 2, 6 and 15 . The numbers $0,2,4,8$ and 10 represent high to low expressions. The vertical axis represents one chicken and horizontal axis refers to a gene

\section{Analysis of COG enrichment}

Annotations of differentially expressed genes against the COG data base showed 3, 6 and 12 DEGs which could not be annotated accurately on day 2, 6 and 15 respectively and were classified in the category of general function prediction only. Based on the number of annotations genes, the second top category on 2 and 15 days was the signal transduction mechanism. However, on day 6 the second top category was Posttranslational modification, protein turnover, chaperones according to the COG database, which suggests that DEGs in the groups of these days may play important roles in TD (Fig. 4).

\section{Analysis of potential KEGG pathways}

We analysed the regulatory pathways of the DEGs using KEGG analysis. The potential KEGG pathways of DEGs on day 2, 6- and 15 are shown in Fig. 4. The KEGG pathways in which most DEGs were enriched on day 2 were calcium signaling pathway, cytokine receptor interaction, MAPK signaling pathway and neuroactive ligand receptor interaction pathway. The KEGG pathways in which most DEGs were enriched on day 6 were the ribosome pathway and MAPK signaling pathway. Most DEGs enriched on day 15 in KEGG pathways were regulation of actin cytoskeleton pathway and focal adhesion pathway (Fig. 5, Additional file 4: Figure S4). Moreover, the angiogenesis related pathways found on day 2, 6 and 15 were hedgehog signaling pathway, vascular endothelial growth factor signaling pathway (VEGF) and the Notch signaling pathway (Additional file 4: Figure S4). We selected the top 20 angiogenesis related genes belonging to these pathways for further confirmation under qPCR experiment.

\section{Screening of DEGs and qPCR}

Screening of differentially expressed angiogenesis genes were done based on their enrichment in the KEGG pathways, COG and GO annotations. Selected DEGs for further confirmation under qPCR experiment were $C L U$, F13A1, TBXA2R, IL1R1, RPL17, RAC2, RAP1B, GIT1, IQGAP2, ITGAV, ITGA2, ITGB2, ITGB3, ITGA5, Vavlike, FYN, PTPN11, NCOR2, MAML3 and PTCH1 (Additional file 3: Table S2).

The angiogenesis related DEGs $(n=20)$ were analysed by qPCR for further confirmation $(n=3$, same as RNAseq). The results revealed that all 20 genes were validated with DEGs data (Fig. 6). The level of expressions of F13A1, CLU, TBXA2R and IL1R1 genes were upregulated in the thiram group on day 2. The DEGs RPL17 and $P T C H 1$ were downregulated in the thiram group on day 6. Whereas on day 15, ITGB3, ITGAV, ITGB2, RAC2, ITGA2, IQGAP2, GIT1, VAV1, ITGA5, RAP1B, FYN, PTPN11, NCOR2, and MAML3 genes were downregulated in the thiram group. Transcriptome sequencing and qRT-PCR results of 20 differentially expressed angiogenesis related genes observed in the same range for day 2 and 6 . In addition, the transcriptome sequencing result of day 15 is also consistent with qRT-PCR result but the range of fold change does not follow each other. 


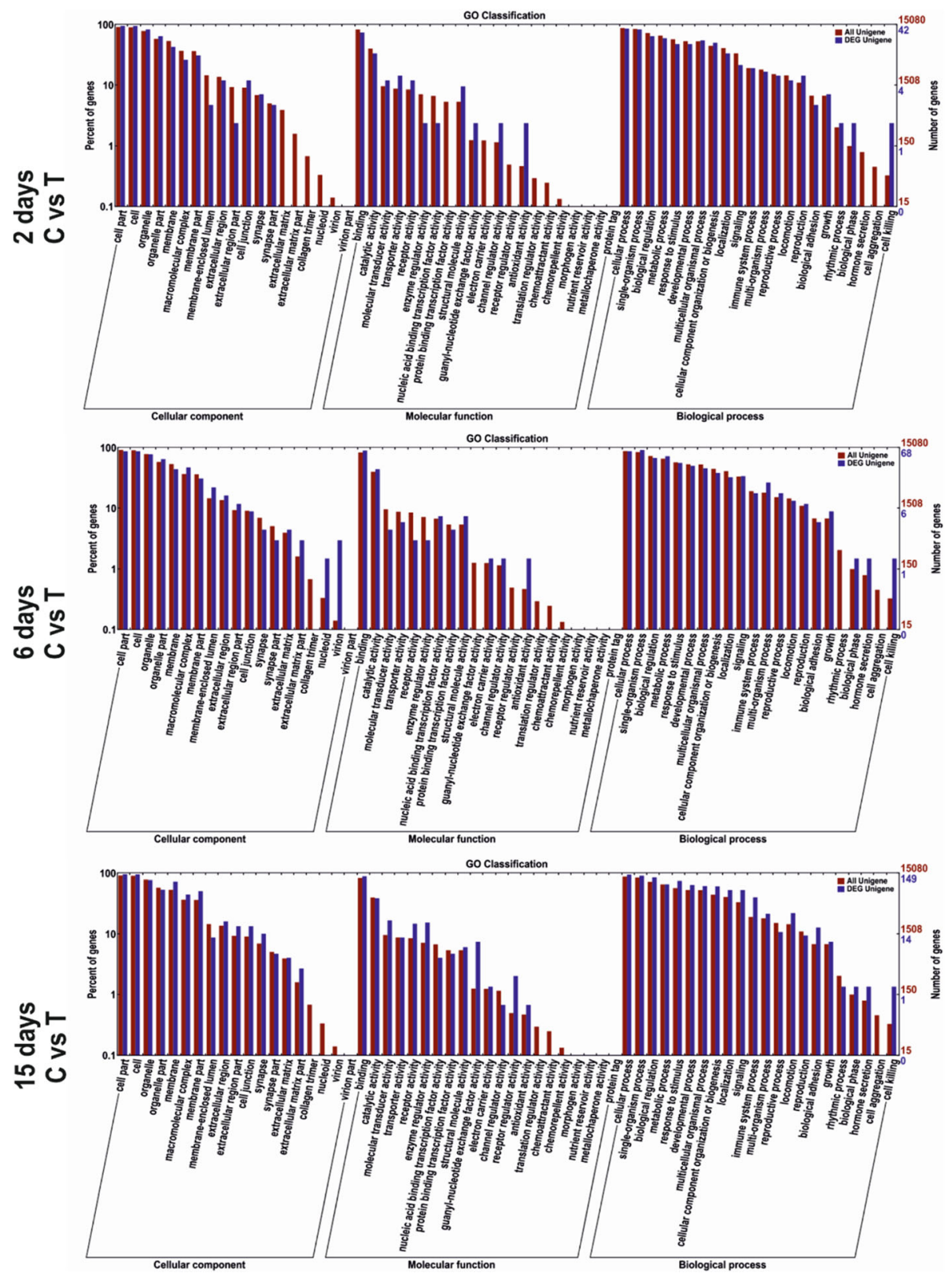

Fig. 3 Gene ontology classifications. The differentially expressed genes were assigned in three categories of GO classifications: Cellular component, molecular function, and biological process. $C=$ control, $T=$ thiram

\section{Discussion}

In this study, the differentially expressed angiogenesisrelated genes of erythrocytes were identified and investigated on different stages of thiram induced TD in broilers. DEGs were screened by transcriptome sequencing on day 2, 6 and 15. Subsequently, 293 differentially expressed genes appeared on day 2 (49 DEGs), day 6 (80 DEGs) and day 15 (164 DEGs), respectively. Secondly, the functions of DEGs were annotated by COG, GO, and KEGG databases and 20 angiogenesis related DEGs and their enrichment pathways were analysed to elucidate the role of angiogenesis and erythrocytes in thiram induced TD. Finally, the RNA sequence was validated by qPCR.

Previously, transcriptome sequencing in TD was mainly focused in early stage [2], but this study reported early and late changes of erythrocytes in thiram induced TD. Thiram is lipophilic in nature and combined with the cell membrane to cause cytotoxicity, bone formation disorder, cartilage cell damage and immune depressions. It can also cause membrane damage, bone morphogenic inactivation and inhibit angiogenesis [12, 13]. In TD, a large number of the cartilage cell damage is due to the apoptosis process 

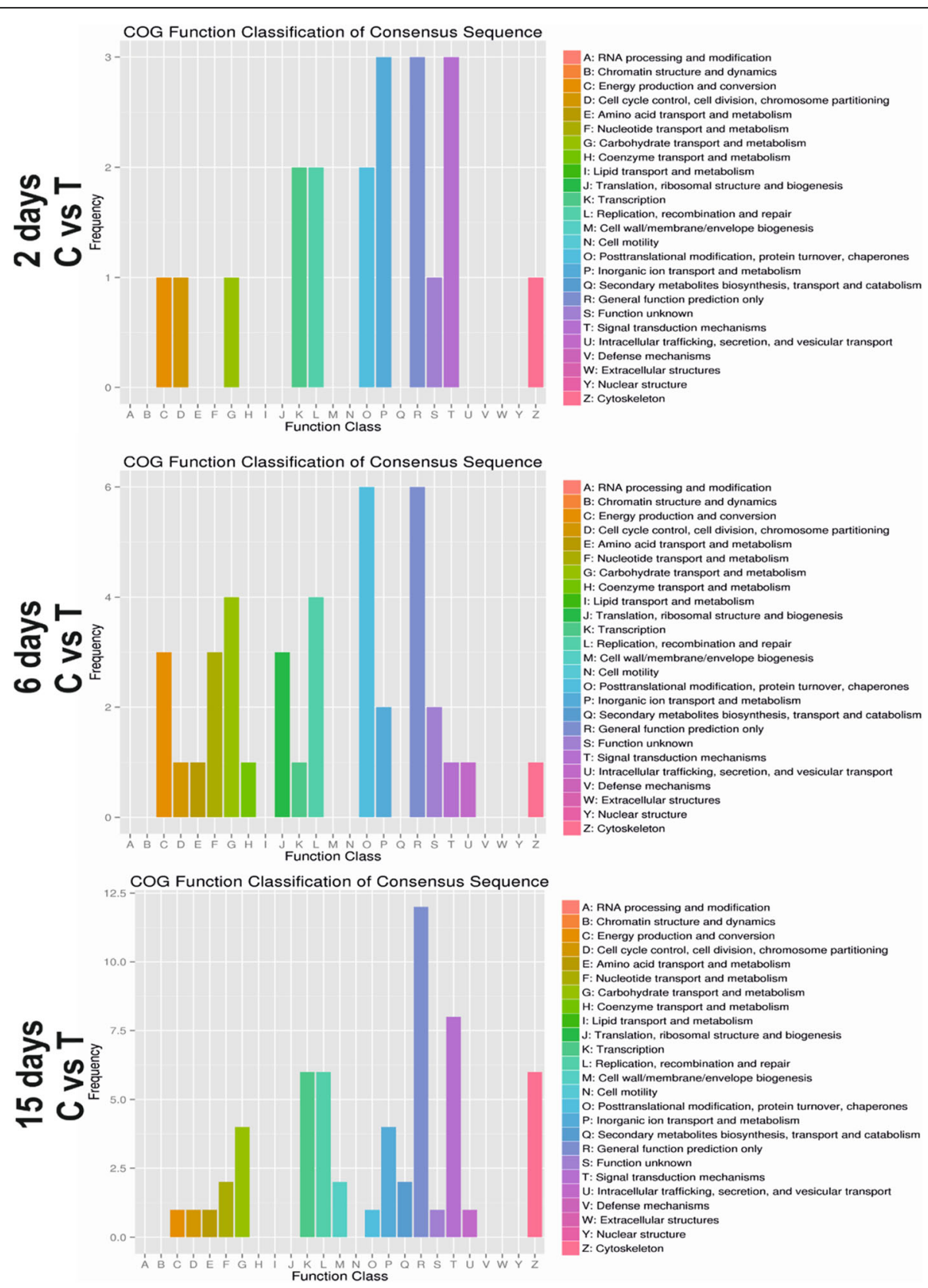

Fig. 4 COG function classification. The COG function classification of the consensus sequences. The number of genes shown on horizontal and proportions plotted on the vertical axis. $C=$ control, $T=$ thiram

and abnormal protein secretion in the cartilage cells, causing a decrease in the cartilage extracellular matrix degradation rate, which limits the space for bone deposition [14, 15]. The cells stop to multiply and endure hypertrophy and apoptosis in tibia bone. Thiram destroyed the regular column of chondrocytes and the number of cells is decreased in the tibial growth plate of chickens [13]. In TD, the cells in hypertrophic zone were degraded, dead and arranged in irregular columns, having no nucleus in it [16]. This study showed that there were more lesions and fewer blood vessels in the growth plate of thiram-fed chickens. The blood vessels started sprouting in the thiram group on late stages when some area of the growth plate had become calcified and vascularized after the severity of lesions. Hematoxylin and eosin result also revealed that the proliferation of chondrocytes was affected, as their size and shape were degraded, and arrangements were disordered in the early stage, and recovered at a later stage. The blood vessels were severely affected at an early stage and started getting recover later. This research found the 


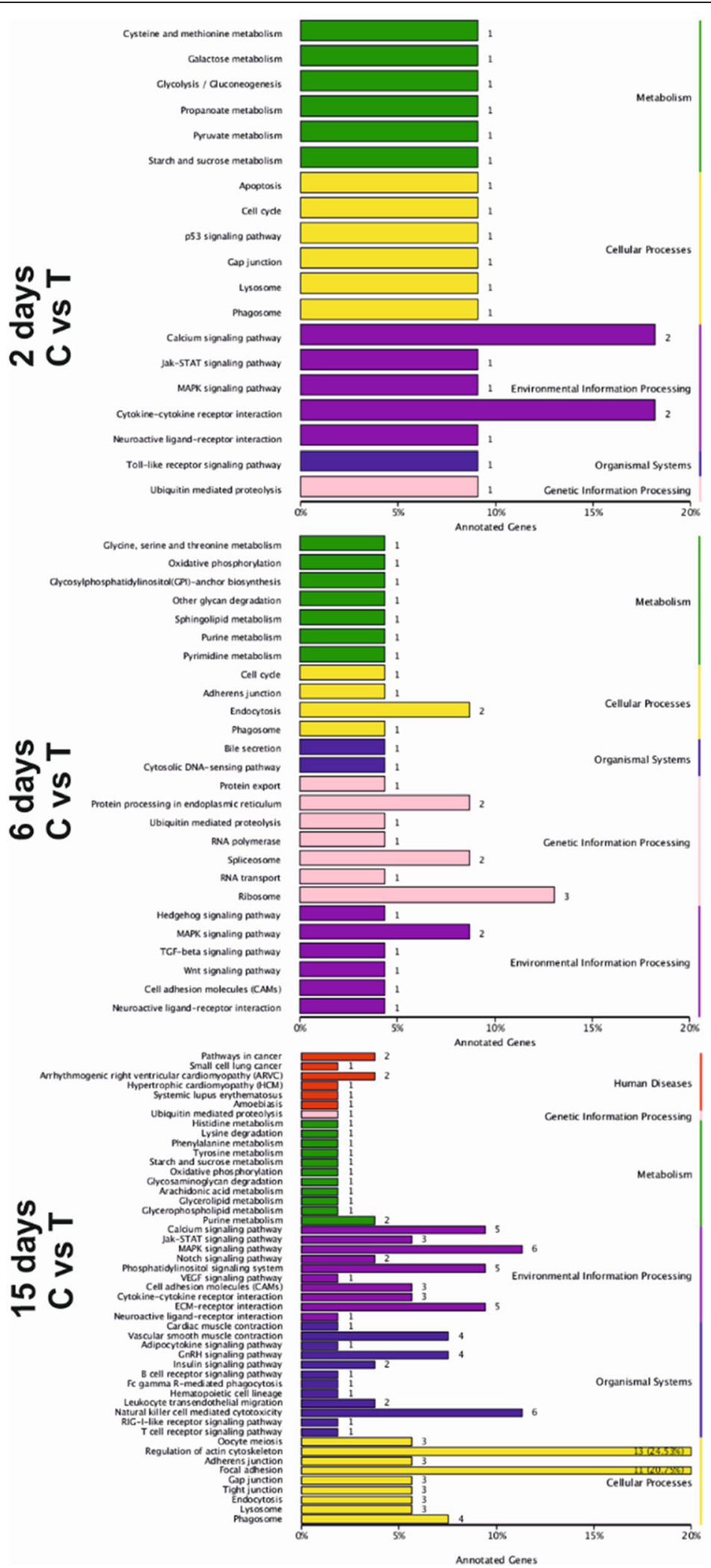

Fig. 5 KEGG categories. The KEGG categories of DEGs. The vertical axis shows the metabolic pathways and the horizontal axis shows the proportion of annotated genes. $C=$ control, $T=$ thiram 


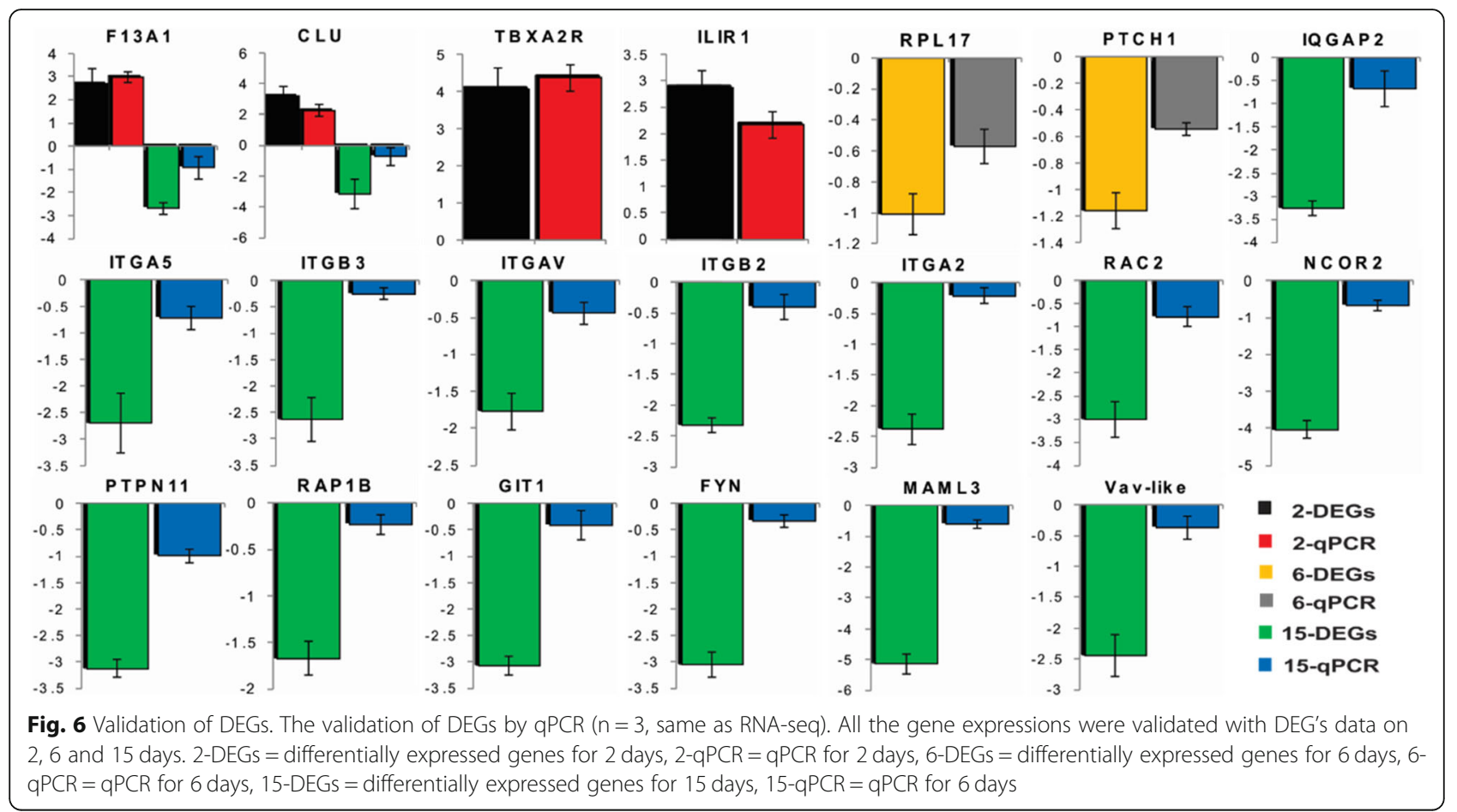

erythrocytes in the chondrocytes of broiler chickens that is a rare case of its type, so we designed this study to guess the function of erythrocytes concerned to angiogenesisrelated genes of erythrocytes.

The differentially expressed common genes on day 2, 6 and 15 were UBE2R2, CCSAP, ATP2A $3, F 13 A 1$, $S H R O O M 2, R A S A 3$, and $C L U$. Firstly, UBE2R2 noticed significantly downregulated on day 2 and upregulated on day 6. Furthermore, COG categories of function classification regarding protein turnover was enriched on day 6 , which guess that thiram induce TD increases the level of $U B E 2 R 2$ to degrade the proteins in the chickens. Previous research supports our findings, as ubiquitin conjugating enzymes including $U B E 2 R 2$ is responsible to degrade the proteins through proteasome [17]. HIF- $1 \alpha$ is one of the major client proteins of heat-shock protein 90 (Hsp90), and it is required for the functioning and the rapid hypoxic stabilization of HIF-1 $\alpha$, which is degraded by the ubiquitin-proteasome protein system [18]. In addition, this is the first finding related to $U B E 2 R 2$ in thiram induced TD chickens. Secondly, $A T P 2 A 3$ was upregulated on day 2 and downregulated on day 15, which have been evaluated previously as a transporter of $\mathrm{Ca}^{+2}$ ions [19]. A recent study reported that $\mathrm{Ca}^{+2}$ ions decreased in TD chickens [20]. KEGG pathways results of our study demonstrated that calcium signaling pathway was not enriched and differentially expressed on day 6 , which was the clear indication of decreased or less $\mathrm{Ca}+$ ions transportation compared on day 2 and 15 . The results of this study supported and added in the findings of Huang et al., [20], thiram significantly downregulated the expression of $A T P 2 A 3$, which could be responsible for the reduction of $\mathrm{Ca}^{+2}$ ions transportation similarly in TD chickens. Moreover, calcium signaling pathway shows that the chickens are being recovered from the deleterious effect of thiram on day 15. Thirdly, Shroom2 was upregulated on day 2 and downregulated on day 15 . It has an important role to develop vasculature, which is required for proper angiogenesis; reduction in which decrease the endothelial contractility and cause sprouting [21]. Fourthly, RASA3 is a GTPase activating protein of the GAP1 family, targets the R-Ras and Rap1 [22]. Rap1 signaling is important for angiogenesis from pre-existing ones [23]. RASA3 have been found upregulated on day 2 and downregulated on day 15 , although not differentially expressed on day 6. It can be illustrated that angiogenesis is developing on day 2, in contrast to day 6 and sprouting developed from pre-existing ones on day 15 . Fifthly, CLU defends the apoptosis and necrosis of cells induced by the genotoxic and oxidative stress [24]. In our study, $C L U$ upregulated on day 2 and downregulated on day 15 . Whereas on day 6 , it was not differentially expressed. Sixthly, F13A1 is a key molecule, which coagulates the blood and, played role in angiogenesis and tissue repairing when interacts with vascular endothelial growth factor receptor 2 (VEGFR2) and integrin $\alpha \mathrm{V} \beta 3$ for optimal tissue healing [25]. Seventhly, CCSAP is the only gene which differentially expressed and upregulated on both 2 and 15 days. Its role is not cleared yet, even though very limited literature is available which 
demonstrated that it localizes to polyglutamylated microtubules and promotes proper cilia function and embryonic development [26]. Another study reported that proper expression of CCSAP is required for normal mitotic progression [27]. Based on the results of our study and previous reports, it could be demonstrated that CCSAP is responsible for the stability of erythrocytes in thiram induced TD chickens.

The annotation function of differentially expressed genes in the KEGG database explored 7 enriched pathways with most DEGs on 2, 6 and 15 days were neuroactive ligand receptor interaction, MAPK signaling, ribosomes, regulation of actin cytoskeleton, focal adhesion and natural killer cell mediated cytotoxicity and Notch signaling pathways. In this study, we elaborated and predicted the role of above-mentioned pathways in angiogenesis of thiram fed chickens; including some notable DEGs to identify the potential pathways and candidate genes.

The neuroactive ligand-receptor interaction and MAPK signaling pathway were found significantly enriched on day 2, including DEGs TBXA2R and IL1R1. Recent research reported TBXA2R a novel cancer gene, involved in aggregation and activation of platelets, which activate multitude of signaling cascades to control various cellular processes, like vasoconstriction of smooth muscle, responses to inflammation, cell adhesion, motility, proliferation, and the cell survives; showed dramatic cell killing when decreased/downregulated the level of TBXA2R [28, 29]. ILIR1 is the cell surface receptor, which is mediators of inflammation, controls the reactions produced in response to injury or stress. The upregulation of IL1R1 indicated osteoarthritis [30]. This study predicted the expressions of MAPKs started increasing on day 2, in response to stress/injury caused by thiram. It could be stated that the harmful effect of thiram induced TD in chickens started on day 2 . This study agreed to a recent transcriptional study of Malgulwar et al, [31] who concluded that $I L 1 R 1$ could play a role in phenotypic changes of high microvascular densities and increased expressions of VEGF.

The ribosome pathway has been reported to be related to cell growth, proliferation, and apoptosis [32]. It mediated the angiogenesis in response to injury or stress. RPL17 acts as tumor inhibition. If the expression of RPL17 downregulated, it causes the proliferation of VSMC [33]. Immunohistochemistry and $\mathrm{H} \& \mathrm{E}$ staining results of this study evaluated those blood vessels destructed and diminished in thiram group on day 6 as compared to all other groups. It could be stated that thiram significantly downregulated the expressions of ribosomal pathway gene $R P L 17$ on day 6 which resultantly reduced the angiogenesis. The relationship between ribosomal protein functions and angiogenesis has not been studied till date in thiram fed chickens. This is the first ever study of its type, in which the role of $R P$ L17 is elaborated as concerned to thiram fed chickens. Concerned to ribosomal proteins, these results could be valuable for further investigation of angiogenesis and erythrocytes in TD. Formerly, it has already been reported that $R P L 17$ gene might play a role in suppressing angiogenesis [32]. In addition, $R P$ L17 found significantly downregulated in chicken, which causes remodeling through vascular smooth cell proliferation and inflammation [34].

The actin cytoskeleton and focal adhesion pathway are crucial for the cell adhesion, cell motility, and morphological changes, which may impact angiogenesis and cell adhesion to protect the cells from various toxic mediators $[35,36]$. The actin cytoskeleton plays an essential role in maintaining normal functions of a cell by modulating the shape, migration, and proliferation, which are needed for angiogenesis [35].

Transcriptome sequencing results of this study identified several DEGs, involved in the actin cytoskeleton and cell adhesion pathways on day 15 were $R A C 2, R A P 1 \mathrm{~B}$, GIT1, IQGAP2, ITGAV, ITGA2, ITGB2, ITGB3, ITGA5, $V A V 1, F Y N$. DEGs, $R A C 2$, and RAP1B belong to ras family, whereas GIT1 and IQGAP2 belong to GTPaseactivating protein family. Previously, it has also been reported that Ras family and GTPase activating protein family regulate angiogenesis, with controlling the endothelial cell functions [37].

Integrins are the transmembrane receptors which mediate cell extracellular matrix (ECM) adhesion. On ligand binding, integrins activate the signal transduction pathways which facilitates cellular signals such cell cycle regulation, an organization of the intracellular cytoskeleton, and the movement of new receptors to the cell membrane [38]. In our study, the selected enriched DEGs on day 15 were ITGAV, ITGA2, ITGB2, ITGB3, ITGA5, which have been defined as integrin family [39], involved in the cytoskeleton and focal adhesion pathway of this study. Integrins took part in the angiogenesis and considered a potential antiangiogenic target which upregulated in tumor related blood vessels [40, 41]. The results of this study are in line with recent studies of Khalid Mehmood et al., [42], who examined the expression of ITGB3 in thiram treated chickens and found downregulation of ITGB3 gene on day 14. Similarly, we have found ITGB3, including ITGAV, ITGA2, ITGB2, and ITGA5 integrin genes downregulated in TD-effected chickens on day 15 as compared to normal chickens. Khalid Mehmood et., al [42] has found that, the usage of ligustrazine in TD chickens significantly increased the expression of ITGB3 which helps to prevent the TD. We found five integrin family downregulated genes on day 15 of thiram-induced TD chickens-including, ITGB3 and other integrins such as ITGAV, ITGA2, ITGB2, and ITGA5 may have a crucial role in angiogenesis. This is 
the first study on thiram induced TD chickens, which reported the role of integrin family genes in angiogenesis, future research concerned to integrin genes should be focused on it to develop medication in response to increase expressions in TD chickens.

Natural killer (NK) cell-mediated cytotoxicity pathway contributed to the innate immunity to response numerous malignancies, including leukemia [43]. We have found VAV1, FYN, PTPN11 genes involved in (NK) cellmediated cytotoxicity pathway downregulated in thiram induced TD chickens on day 15 . The physiological function of Vav-like gene is restricted to the hematopoietic system, where it plays a critical role in the development and activation of T-cells. Fyn tyrosine kinase participates in several biological processes, such as cell growth and differentiation, it also involved in the pathogenesis of hematologic malignancies $[44,45]$. PTPN11 is one of the few known phosphatases that can function as an oncogene [46] to dephosphorylate the signaling molecules including Fyn, and Vav1, and terminated the activity of signaling receptors in NK cells [47]. The main function of PTPN11 is to suppress the tumor [48]. PTPN11 could play a vital role in promoting angiogenesis in TD chickens, if the expressions of PTPN11 have been upregulated with medication.

The Notch signaling pathway plays an important part in skeletal development and homeostasis. Serious skeletal disorders can be attributed to alterations in the Notch signaling pathway [49]. Notch pathway inhibits the chondrogenesis and arrests chondrocyte differentiation in chicken embryos and prevents the formation of the hypertrophic zone in the growth plate [50]. NCOR2 and MAML3 genes downregulated in the Notch signaling pathway on day 15 in our study. Notch receptor signaling controls the endothelial cell proliferation, adhesion, migration and formation of new blood vessels as angiogenesis [51]. MAML3 is a critical transcriptional co-activator in the Notch signaling pathway, and is encoded by a family of Mastermind like $(M A M L)$ genes [52]. MAML3 encodes transcriptional co-activators for the Notch signaling pathway [52]. NCOR2 also known as silencing mediator of retinoid and thyroid hormone (SMRT) is a potent regulator of retinoid and thyroid hormone signalling [53] which repress inflammatory response genes [54]. The role of NCOR2 in TD chicken is still unclear, but we predicted that Notch signaling pathway gene NCOR2 repress the inflammatory response of thiram in TD chickens.

\section{Conclusion}

In this study, we have found potential target genes concerned to angiogenesis and erythrocytes which control the blood circulation. To prevent TD in broiler chickens, some therapeutic interventions are needed to regulate these genes, such as $A T P 2 A 3, U B E 2 R 2$, CCSAP, F13A1, $S H R O O M 2, R A S A 3$, and $C L U$, which expressed commonly in the erythrocytes within the trial groups. DEGs (TBXA2R, IL1R1, RPL17, ITGB3, ITGAV, ITGB2, RAC2, ITGA2, IQGAP2, GIT1, VAV1, ITGA5, RAP1B, FYN, PTPN11, PTCH1, NCOR2, MAML3) of potential pathways (Neuroactive ligand receptor interaction, MAPKs, ribosomes, regulation of actin cytoskeleton, focal adhesion, natural killer cell mediated cytotoxicity and the Notch signaling pathway) have important role in angiogenesis concerned to thiram induced TD chickens, most importantly integrin family, ribosome pathway and RPL17 gene. However, future research is needed to make medicine which can regulate these genes.

\section{Methods}

\section{Induction of TD and blood collection}

One day old broiler chickens $(n=24)$ were purchased from Shanxi Daxiang Farming Group (Shanxi, China), and fed ad-libitum basal diet for 7 days. After overnight fasting on seventh day, all the 24 broilers were randomly allotted into the control and the thiram groups. The broilers in thiram groups were fed a diet containing 100 $\mathrm{mg} / \mathrm{kg}$ thiram for $48 \mathrm{~h}$ to induce TD [2]. Four birds from each group were sacrificed by cervical dislocation under euthanasia on day 2,6 , and 15 after the thiram feed. Day 2 and 6 (8- and 14-days old chicken) were differentiated as early stage TD chickens, and day 15 (23 days old chickens) were differentiated as late stage TD chickens.

The broilers were bled $(2.5 \mathrm{~mL})$ from a brachial vein on day 2, 6 and 15 to collect blood samples and then sacrificed [55]. Before exsanguination and necropsy, injection of pentobarbital was used in conjunction with the standard protocols of euthanasia to minimize suffering. All the procedures complied with the welfare guidelines approved by the College of Animal Science and Veterinary Medicine of Shanxi Agricultural University, China (Number 88, 2010).

\section{Morphology, histology, and immunohistochemistry}

The experimental chickens $(n=4)$ were sacrificed on day 2, 6 and 15 after thiram feed. The tibiae from allotted chickens were immediately taken out after the chickens were sacrificed. Then, left sagittal sections of the proximal tibial growth plate were prepared for morphological analysis [56]. Right proximal tibiae were fixed in $4 \%$ paraformaldehyde and H\&E staining was performed as mentioned in our previous article [2]. Furthermore, IHC was used for analysing the expression of angiogenesisrelated genes integrin alpha-v precursor (ITGAV) and clusterin precursor (CLU), which were deparaffinized in xylene, and rehydrated through series of graded ethanol solutions, rinsed in distilled water, and incubated in 3\% $\mathrm{H}_{2} \mathrm{O}_{2}$ [57]. ITGAV and CLU were detected and localized 
at the cellular level by IHC with rabbit anti-integrin and anti-clusterin (BS9178; Bio world, Nanjing, China). The Immunohistochemistry (IHC) scoring system was used to determine the scores of ITGAV and CLU expression [58]. Furthermore, the quantification of $H \& E$ staining was analysed in ImageJ software. The relative area of blood vessels determined in percentage by dividing area of interest of blood vessels with total area (Pixels $4080 \times$ 3072), and the density of blood vessels were measured using ImageJ 1.42q software.

RNA extraction, library construction, and RNA-sequencing To extract RNA, the chicken blood samples $(2.5 \mathrm{~mL})$ of control and thiram groups ( $n=3$ randomly) were collected on day 2, 6 and 15. Total RNA was extracted from the erythrocytes of each group on day 2, 6 and 15 using TRIzol reagent (Invitrogen, Carlsbad, CA, USA) as Niu et al., [10, 11].

Library construction and RNA-Seq were performed at Beijing BioMarker Technologies (Beijing, China) in accordance with the institute's protocols and are briefly described here. RNA purity was checked using a NanoPhotometer spectrophotometer (IMPLEN, CA, USA). RNA concentration was measured by the Qubit RNA Assay Kit in a Qubit 2.0 Flurometer (Life Technologies, CA, USA). RNA integrity was assessed using the RNA Nano 6000 Assay Kit of the Agilent Bioanalyzer 2100 system (Agilent Technologies, CA, USA). A total amount of $1 \mathrm{mg}$ RNA per sample was used as input material for the RNA sample preparations. Sequencing libraries were generated using the NEBNext UltraTM RNA Library Prep Kit for Illumina (NEB, USA) following the manufacturer's recommendations and index codes were added to identify sequences for each sample. mRNA was isolated by NEBNext Poly (A) mRNA Magnetic Isolation Module (NEB, E7490). The cDNA library was constructed following the manufacturer's instructions of NEBNext Ultra RNA Library Prep Kit for Illumina (NEB, E7530) and NEBNext Multiplex Oligos for Illumina (NEB, E7500). In brief, the enriched mRNA was fragmented into approximately $200 \mathrm{nt}$ RNA inserts, which were used to synthesize the first-strand cDNA and the second cDNA. The double-stranded cDNA was performed end- repair/dA-tail and adaptor ligation. The suitable fragments were isolated by Agencourt AMPure XP beads (Beckman Coulter, Inc.). Then $3 \mu$ l USER Enzyme (NEB, USA) was used with size-selected, adaptorligated cDNA at $37^{\circ} \mathrm{C}$ for $15 \mathrm{~min}$ followed by $5 \mathrm{~min}$ at $95^{\circ} \mathrm{C}$ before PCR. Then PCR was performed with Phusion High-Fidelity DNA polymerase, Universal PCR primers and Index (X) Primer. At last, PCR products were purified (AMPure XP system) and library quality was assessed on the Agilent Bioanalyzer 2100 system. Finally, the cDNA libraries of the chicken (Gallus gallus) were sequenced on a flow cell using an Illumina HiSeq 2500 sequencing platform.

\section{Transcriptome analysis using reference genome-based reads mapping}

Low quality reads, such as adaptor sequences, unknown nucleotides $>5 \%$, or low Q-value $(\leq 20)$ base more than $20 \%$, were removed by perl script. The clean reads that were filtered from the raw reads were mapped to chicken genome (Gallus gallus 5.0) using Tophat2 [59] software. The aligned records from the aligners in BAM/SAM format were further examined to remove potential duplicate molecules. Gene expression levels were estimated using FPKM values (fragments per kilo base of exon per million fragments mapped) by the Cufflinks software [60].

\section{Identification of differential gene expression}

The differential expression analysis of two groups was performed using the DESeq R package (1.10.1). DESeq [61] provide statistical routines for determining differential expression in digital gene expression data using a model based on the negative binomial distribution. The resulting $P$ values were adjusted using the Benjamini and Hochberg's approach for controlling the false discovery rate. Genes with an adjusted $P$-value $<0.05$ found by DESeq were assigned as differentially expressed.

\section{Sequence annotation}

Genes were compared against various protein database by BLASTX, including the National Center for Biotechnology Information (NCBI) non-redundant protein $(\mathrm{Nr})$ database, Swiss-Prot database with a cut-off E-value of 10-5. Furthermore, genes were searched against the NCBI nonredundant nucleotide sequence $(\mathrm{Nt})$ database using BLASTn by a cut-off E-value of 10-5. Genes were retrieved based on the best BLAST hit (highest score) along with their protein functional annotation. To annotate the gene with gene ontology (GO) terms, the Nr BLAST results were imported into the Blast2 $\mathrm{GO}$ program [62]. GO annotations for the genes were obtained by Blast2 GO. This analysis mapped all the annotated genes to GO terms in the database and counted the number of genes associated with each term. Perl script was then used to plot GO functional classification for the unigenes with a GO term hit to view the distribution of gene functions. The obtained annotation was enriched and refined using TopGo ( $\mathrm{R}$ package). The gene sequences were also aligned to the Clusters of Orthologous Group (COG) database to predict and classify functions [63]. KEGG pathways were assigned to the assembled sequences by Perl script.

\section{Confirmation using quantitative real-time PCR}

To validate the transcriptome sequencing data, 20 differentially expressed genes related to angiogenesis were 
selected from potential pathway on 2, 6 and 15 days for Real-time PCR, ( $n=3$, same as RNA-seq) using a TaKaRa SYBR Premix Ex Taq TM II (RR820A; Takara Bio Inc., Dalian, China) by the Quant Studio ${ }^{\mathrm{Tm}} 6$ (Applied
Biosystems, America). Primer sequences, annealing temperature, and accession numbers are shown in Table 1. Reactions contained $1 \mu \mathrm{L}$ of cDNA, $0.15 \mu \mathrm{L}$ of each forward and reverse primer $(10 \mathrm{pmol} / \mu \mathrm{L}), 6 \mu \mathrm{L} 1 \times \mathrm{SYBR}$

Table 1 Primers used in real-time PCR analysis

\begin{tabular}{|c|c|c|c|c|}
\hline Genes & Primers & Size (BP) & Annealing $\mathrm{T}\left({ }^{\circ} \mathrm{C}\right)$ & Accession N0. \\
\hline \multirow[t]{2}{*}{ F13A1 } & F: GGATGCTITTGGTCTGATAC & 100 & $55^{\circ} \mathrm{C}$ & NM_204685.1 \\
\hline & R: CTGCTTGTTGATCTCATTGG & & & \\
\hline \multirow[t]{2}{*}{$C L U$} & F: CGTCAGTTCGGTTGGGTCTT & 100 & $55^{\circ} \mathrm{C}$ & NM_204900.1 \\
\hline & R: CCTCGAGGTTGGGAGTITTG & & & \\
\hline \multirow[t]{2}{*}{ TBXA2R } & F: GACAGCGAAGTGGAGATGAT & 100 & $55^{\circ} \mathrm{C}$ & XM_015299775.1 \\
\hline & R: GGAGAGTGGTCTGGATGATG & & & \\
\hline \multirow[t]{2}{*}{ ILIR1 } & F: TTCACGCACCATGAATCTG & 100 & $55^{\circ} \mathrm{C}$ & NM_205485.1 \\
\hline & R: GAGCCGAGTTCCACTTCAAT & & & \\
\hline \multirow[t]{2}{*}{ RPL17 } & F: GTGAACAAGGCTCCCAAAAT & 100 & $55^{\circ} \mathrm{C}$ & NM_001282277.1 \\
\hline & R: CGGTGAGGATCATCTCAATG & & & \\
\hline \multirow[t]{2}{*}{ ITGB3 } & F: TTTGTGGACAAGCCCATTTC & 100 & $55^{\circ} \mathrm{C}$ & NM_204315.1 \\
\hline & R: CAAACATGGGCAAGCACTIT & & & \\
\hline \multirow[t]{2}{*}{ ITGAV } & F: TCAGTGGTTTGGAGCATCTG & 100 & $55^{\circ} \mathrm{C}$ & NM_205439.1 \\
\hline & R: AGGCTCTCGCTCTTGTIITG & & & \\
\hline \multirow[t]{2}{*}{ ITGB2 } & F: CAGTGCGTTCAGCAATAAGA & 100 & $55^{\circ} \mathrm{C}$ & NM_205251.1 \\
\hline & R: AGCACGACGAAACTTCACAT & & & \\
\hline \multirow[t]{2}{*}{ RAC2 } & F: GGAGAATACATCCCCACTGT & 100 & $55^{\circ} \mathrm{C}$ & NM_001201452.1 \\
\hline & R: CCTCTTGTCCAGCAGTATCC & & & \\
\hline \multirow[t]{2}{*}{ ITGA2 } & F: TGCTAATAATCCCCGTGTAG & 100 & $55^{\circ} \mathrm{C}$ & XM_015277561.1 \\
\hline & R: CAGATCTCCTCCCTGTTGAA & & & \\
\hline \multirow[t]{2}{*}{ IQGAP2 } & F: CTGGTGAGGCCAGTAAATTG & 100 & $55^{\circ} \mathrm{C}$ & NM_001277778.1 \\
\hline & R: CGCAAACTCTGAATCGATGA & & & \\
\hline \multirow[t]{2}{*}{ GIT1 } & F: CATCACGCTGCAGGAGTACCT & 100 & $55^{\circ} \mathrm{C}$ & NM_204296.1 \\
\hline & R: CTCATCGCTCAGGCTGTTGT & & & \\
\hline \multirow[t]{2}{*}{ VAV1 } & F: CTGGAGACGTTGTAGGGTATG & 100 & $55^{\circ} \mathrm{C}$ & NT_469922.1 \\
\hline & R: TGGTGAGACGGGTTGGTT & & & \\
\hline \multirow[t]{2}{*}{ ITGA5 } & F: CTCCAACTACCCCGAGTACT & 100 & $55^{\circ} \mathrm{C}$ & KC439457.1 \\
\hline & R: CACCGAATAGCCCATATAAC & & & \\
\hline \multirow[t]{2}{*}{ RAP1B } & F: TCGAGTCAAAGACACTGATG & 100 & $55^{\circ} \mathrm{C}$ & NM_001007852.1 \\
\hline & R: TAGGTTCTGACCTTGTTCCT & & & \\
\hline \multirow[t]{2}{*}{ FYN } & F: AGGAGTGGTACTTCGGCAAA & 100 & $55^{\circ} \mathrm{C}$ & NM_205349.2 \\
\hline & R: GTTTCACTTTCCCGGATCAG & & & \\
\hline \multirow[t]{2}{*}{ PTPN11 } & F: TGGAGGCAGAAAATCTACTG & 100 & $55^{\circ} \mathrm{C}$ & NM_204968.1 \\
\hline & R: CGCCTAACAGAGAGAGTGAA & & & \\
\hline \multirow[t]{2}{*}{ PTCH1 } & F: TTCCTTCTAGCCCATGCGTTT & 100 & $55^{\circ} \mathrm{C}$ & NM_204960.2 \\
\hline & R: CTACACTTGCTCCTGTTCGCTIT & & & \\
\hline \multirow[t]{2}{*}{ NCOR2 } & F: GGTCCCACACACTTGAC & 100 & $55^{\circ} \mathrm{C}$ & XM_015275621.1 \\
\hline & R: GGTGGATACTAGGATGGATT & & & \\
\hline \multirow[t]{2}{*}{ MAML3 } & F: GCAACCACACGCTGATCATG & 100 & $55^{\circ} \mathrm{C}$ & XM_015276692.1 \\
\hline & R: CCATCGCAAACTCCATTCTG & & & \\
\hline
\end{tabular}


Premix Ex Taq II, $0.1 \mu \mathrm{L}$ ROX dye II and $2.6 \mu \mathrm{L}$ double distilled $\mathrm{H}_{2} \mathrm{O}$. A template of each group was amplified by using the following protocol: $95^{\circ} \mathrm{C}$ for $3 \mathrm{~min}$, followed by 42 cycles of $95^{\circ} \mathrm{C}$ for $30 \mathrm{~s}, 55^{\circ} \mathrm{C}$ for $30 \mathrm{~s}$, and extension at $72^{\circ} \mathrm{C}$ for $10 \mathrm{~s} .18 \mathrm{~S}$ rRNA was used as the house-keeping gene, the control samples were used as the calibrator, and the expression of each gene is reported as fold change relative to the control group. The qPCR analysis was performed with three biological and technical replicates. The real-time PCR data were analyzed using the $2^{-\Delta \Delta C t}$ method. JMP (version 10) program was used for statistical analysis.

\section{Statistical analysis}

Data are presented as mean and standard deviation (Mean $\pm \mathrm{SD}$ ). The value of $P<0.05$ was considered statistically significant. The quantification data of microscopic figures was obtained with ImageJ $1.42 \mathrm{q}$ software and analyzed by on way ANOVA and student $t$-test to compare the differences between mean values of different groups.

\section{Supplementary information}

Supplementary information accompanies this paper at https://doi.org/10. 1186/s12864-020-6456-9

\section{Additional file 1. List of total DEGs on day 2, 6 and 15. \\ Additional file 2: Table S1. Commonly observed differentially} expressed genes on day 2, 6 and 15

Additional file 3: Table S2. Differentially expressed genes in control and thiram groups on day 2,6 and 15

Additional file 4: Figure S1. Vascularization and calcification. The histopathological observation of tibial growth plate (GP). Calcification and normal blood vessels in the control groups and damaged blood vessels in the treatment groups can clearly be seen in this figure. The relative blood vessels area and erythrocytes were determined with ImageJ software $(\mathrm{Bar}=200 \mu \mathrm{m})$. Figure S2. Quantification of H\&E and IHC. A The relative area of blood vessels determined in percentage by dividing area of blood vessels with total area (Pixels $4080 \times 3072$ ). B The density of blood vessels was measured using ImageJ $1.42 \mathrm{q}$ software to find denser erythrocytes ratio in control and thiram groups. C IHC profile of Image software was used to determine the ITGAV and CLU expression score in control and thiram treated groups. BV = blood vessels; DV = destruction of blood vessels. (Bar-100 $\mu \mathrm{m}) .2 \mathrm{DC}=2$ days control, $2 \mathrm{DT}=2$ days treatment, $6 \mathrm{DC}=6$ days control, $6 \mathrm{DT}=6$ days treatment, $15 \mathrm{DC}=15$ days control, $15 \mathrm{DT}=15$ days treatment, $\mathrm{C}=$ control, $\mathrm{T}=$ treatment, $\%=$ percentage. The quantification data of H\&E staining and $\mathrm{IHC}$ was obtained by ImageJ software. $* P<0.05 ; * * P<0.01$. Figure S3. Quantification of IHC. Immunohistochemical localization of ITGAV and CLU in control and thiram treated groups. The results were analyzed by ImageJ software using IHC profile plugin. Figure S4. The scatter plot of DEGs enriched in KEGG pathways. The rich factor represents the ratio of DEGs and all unigenes numbers in the pathways; the $Q$ value represents the corrected $P$-value. $C=$ control, $T=$ thiram.

\section{Abbreviations}

ATP2A3: Sarcoplasmic/endoplasmic reticulum calcium ATPase 3; AvBDs: Avian $\beta$-defensins; CCSAP: Centriole cilia and spindle-associated protein; CLU: Clusterin precursor; DEGs: Differentially expressed genes; F13A1: Coagulation factor XIII A chain protein; FYN: Tyrosine-protein kinase Fyn-like; GIT1: ARF GTPase-activating protein; GO: Gene ontology; HDPs: Host defense peptides; IL1R1: Interleukin-1 receptor type 1 precursor; IQGAP2: IQ motif containing GTPase activating protein 2; ITGA2: Integrin alpha-2;
ITGA5: Integrin alpha-IIb-like; ITGAV: Integrin alpha-v precursor; ITGB2: Integrin beta-2 precursor; ITGB3: integrin beta-3 precursor; KEGG: Kyoto Encyclopedia of Genes and Genomes; LEAP-2: Liver-expressed antimicrobial peptide 2; MAML3: Mastermind-like protein 3; MAPK: Mitogen-activated protein kinase; MDV: Mareks disease virus; NCOR2: Nuclear receptor corepressor 2; NK: Natural killer; PTCH1: Protein patched homolog 1; PTPN11: Tyrosineprotein phosphatase non-receptor type 11; RAC2: Ras-related C3 botulinum toxin substrate 2; RAP1B: Ras-related protein Rap-1b precursor; RASA3: Ras GTPase-activating protein 3; RPL 17: Ribosomal protein L17; SHROOM2: Shroom2 isoform X6; TBXA2R: Thromboxane A2 receptor; TD: Tibial dyschondroplasia; Thiram: Tetramethyl thiuram disulfide; UBE2R2: Ubiquitin-conjugating enzyme E2 R2; VAV1: Proto-oncogene vav; VEGF: Vascular endothelial growth factor signaling pathway; VEGFR2: Vascular endothelial growth factor receptor 2

\section{Acknowledgements}

We would like to thank Izhar Mithal Jiskani for critically reading the manuscript and providing important suggestions for improving the manuscript.

\section{Authors' contributions}

A-RJ, H-CC and W-XT conceived and designed the experiments; DZ and SN analyzed the data; A-RJ, SN, R-AM, AfK, M-FQ and AjK performed the experiments and suggested analyses; A-RJ wrote the paper; A-RJ and W-XT revised the manuscript. All authors read and approved the final draft of the manuscript.

\section{Funding}

This work was supported by the Shanxi Scholarship Council of China (2017073), Key scientific and technological innovation platform of Jinzhong (P171002-3), The National Key R \& D Program (2016YFD0500800), Key Technologies R \& D Program of Shanxi Province (20130311027-3), the National Natural Science Foundation of China (31072179) and "131" leading talent project of Colleges and universities in Shanxi province. All these funds provided financial support in the design of the study and collection, analysis, and interpretation of data and in writing the manuscript.

\section{Availability of data and materials}

All data generated or analyzed during this study are included in this published article and its supplementary information files. The datasets are also available from the corresponding author on reasonable request.

\section{Ethics approval and consent to participate}

The management of the experimental animals was in agreement with the welfare guidelines approved by the College of Animal Science and Veterinary Medicine of Shanxi Agricultural University, China (Number 88, 2010)

\section{Consent for publication}

Not applicable.

\section{Competing interests}

The authors declare that they have no competing interests.

\section{Author details}

${ }^{1}$ College of Animal Science and Veterinary Medicine, Shanxi Agricultural University, Taigu 030801, China. ${ }^{2}$ The State Key Laboratory of Agricultural Microbiology, College of Veterinary Medicine, Huazhong Agricultural University, Wuhan 430070, China.

Received: 10 February 2019 Accepted: 7 January 2020 Published online: 15 January 2020

\section{References}

1. Rath N, Huff W, Huff G. Thiram-induced changes in the expression of genes relating to vascularization and tibial dyschondroplasia. Poult Sci. 2007;86: 2390-5.

2. Tian WX, Li JK, Qin P, Wang R, Ning GB, Qiao JG, et al. Screening of differentially expressed genes in the growth plate of broiler chickens with tibial dyschondroplasia by microarray analysis. BMC Genomics. 2013;14:276. 
3. Rath N, Richards M, Huff W, Huff G, Balog J. Changes in the tibial growth plates of chickens with thiram-induced dyschondroplasia. J Comp Pathol. 2005;133:41-52.

4. Huang S, Zhang L, Rehman MU, labal MK, Lan Y, Mehmood K, et al. High altitude hypoxia as a factor that promotes tibial growth plate development in broiler chickens. PLoS One. 2017;12:e0173698.

5. Rasaputra KS, Liyanage R, Lay JO Jr, Slavik MF, Rath NC. Effect of thiram on avian growth plate chondrocytes in culture. J Toxicol Sci. 2013;38:93-101.

6. Tian W, Li J, Bi D, Zhang Y, Qin P. Effect of thiram on growth performance and histopathologic changes of Tibial Dyschondroplasia in broiler chickens. Chin J Anim Vet Sci. 2008:39:733-8.

7. Morera D, MacKenzie SA. Is there a direct role for erythrocytes in the immune response? Vet Res. 2011;42:89.

8. Paolucci S, Barjesteh N, Wood RD, Sharif S. Chicken erythrocytes respond to toll-like receptor ligands by up-regulating cytokine transcripts. Res Vet Sci. 2013;95:87-91

9. Huang SC, Rehman MU, Lan YF, Qiu G, Zhang H, labal MK, et al. Tibial dyschondroplasia is highly associated with suppression of tibial angiogenesis through regulating the HIF-1alpha/NEGF/NEGFR signaling pathway in chickens. Sci Rep. 2017;7:9089.

10. Niu S, Jahejo AR, Jia FJ, Li X, Ning GB, Zhang D, et al. Transcripts of antibacterial peptides in chicken erythrocytes infected with Marek's disease virus. BMC Vet Res. 2018;14:363.

11. Niu S, Jahejo AR, Jia FJ, Li X, Ning GB, Zhang D, et al. The mRNA expression of host defense peptides in chicken erythrocytes are highly related to Tibial Dyschondroplasia and induced by recombinant glutathione-S-Transferase A3 protein. Pak J Zool. 2019:51:1475-82.

12. Beckmann R, Houben A, Tohidnezhad M, Kweider N, Fragoulis A, Wruck C, et al. Mechanical forces induce changes in VEGF and VEGFR-1/sFlt-1 expression in human chondrocytes. Int J Mol Sci. 2014;15:15456-74.

13. Zhang $H$, Mehmood $K$, Jiang $X$, Yao W, labal M, Waqas $M$, et al. Effect of tetramethyl thiuram disulfide (thiram) in relation to tibial dyschondroplasia in chickens. Environ Sci Pollut Res. 2018;25:28264-74.

14. Velada I, Capela-Silva F, Reis F, Pires E, Egas C, Rodrigues-Santos P, et al. Expression of genes encoding extracellular matrix macromolecules and metalloproteinases in avian tibial dyschondroplasia. J Comp Pathol. 2011; 145:174-86.

15. Shim M, Karnuah A, Anthony N, Pesti G, Aggrey S. The effects of broiler chicken growth rate on valgus, varus, and tibial dyschondroplasia. Poult Sci. 2012:91:62-5.

16. lqbal M, Zhang H, Mehmood K, Li A, Jiang X, Wang Y, et al. Icariin: a potential compound for the recovery of Tibial Dyschondroplasia affected chicken via up-regulating BMP-2 expression. Biol Proc Online. 2018;20(1):15.

17. Piper RC, Dikic I, Lukacs GL. Ubiquitin-dependent sorting in endocytosis. Cold Spring Harb Perspect Biol. 2014;6:a016808.

18. Katschinski D, Le L, Schindler S, Thomas T, Voss A, Wenger R, et al. Interaction of the PAS B domain with HSP90 accelerates hypoxia-inducible factor-1a stabilization. Cellular Phys Biochem. 2004;14:351-60

19. Jonchere V, Brionne A, Gautron J, Nys Y. Identification of uterine ion transporters for mineralisation precursors of the avian eggshell. BMC Physiol. 2012;12:10.

20. Huang S, Zhang LH, Zhang JL, Rehman MU, Qiu G, Jiang X, et al. Role and regulation of growth plate vascularization during coupling with osteogenesis in tibial dyschondroplasia of chickens. Sci Rep. 2018;8: 3680

21. Farber MJ, Rizaldy R, Hildebrand JD. Shroom2 regulates contractility to control endothelial morphogenesis. Mol Biol Cell. 2011;22:795-805.

22. Molina OP, Orban T, Martin M, Habets A, Dequiedt F, Schurmans S. Rasa3 controls turnover of endothelial cell adhesion and vascular lumen integrity by a Rap1-dependent mechanism. PLoS Genet. 2018;14:e1007195.

23. Chrzanowska WM. Distinct functions for Rap1 signaling in vascular morphogenesis and dysfunction. Exp Cell Res. 2013;319:2350-9.

24. Song HB, Jun HO, Kim JH, Yu YS, Kim KW, Min BH, et al. Anti-apoptotic effect of clusterin on cisplatin-induced cell death of retinoblastoma cells. Oncol Rep. 2013;30:2713-8

25. Gemmati D, Vigliano M, Burini F, Mari R, Hossam Abd El Mohsein H, Parmeggiani F, et al. Coagulation factor XIIIA (F13A1): novel perspectives in treatment and pharmacogenetics. Curr Pharm Des. 2016;22:1449-59.

26. Backer CB, Gutzman JH, Pearson CG, Cheeseman IM. CSAP localizes to polyglutamylated microtubules and promotes proper cilia function and zebrafish development. Mol Biol Cell. 2012;23:2122-30.
27. Ohta S, Hamada M, Sato N, Toramoto I. Polyglutamylated tubulin binding protein C1orf96/CSAP is involved in microtubule stabilization in mitotic spindles. PLoS One. 2015;10:e0142798.

28. Huang S, Ramamurthy SK, Lin X, Le Breton GC. Cell signalling through thromboxane A2 receptors. Cell Signal. 2004;16:521-33.

29. Orr K, Buckley NE, Haddock $P$, James C, Parent J-L, McQuaid S, et al. Thromboxane A2 receptor (TBXA2R) is a potent survival factor for triple negative breast cancers (TNBCs). Oncotarget. 2016;7:55458.

30. Kato H, Matsumine A, Wakabayashi T, Hasegawa M, Sudo A, Shintani K, et al. Large-scale gene expression profiles, differentially represented in osteoarthritic synovium of the knee joint using cDNA microarray technology. Biomarkers. 2007;12:384-402.

31. Malgulwar PB, Sharma V, Tomar AS, Verma C, Nambirajan A, Singh M, et al. Transcriptional co-expression regulatory network analysis for snail and slug identifies IL1R1, an inflammatory cytokine receptor, to be preferentially expressed in ST-EPN-RELA and PF-EPN-A molecular subgroups of intracranial ependymomas. Oncotarget. 2018:9:35480.

32. Zhou X, Liao W-J, Liao J-M, Liao P, Lu H. Ribosomal proteins: functions beyond the ribosome. J Mol Cell Biol. 2015;7(2):92-104.

33. Smolock EM, Korshunov VA, Glazko G, Qiu X, Gerloff J, Berk BC. Ribosomal protein L17, RpL17, is an inhibitor of vascular smooth muscle growth and carotid intima formation. Circulation. 2012;126(20):2418-27.

34. Yang F, Cao H, Xiao Q, Guo X, Zhuang Y, Zhang C, et al. Transcriptome analysis and Gene identification in the pulmonary artery of broilers with Ascites syndrome. PLoS One. 2016;11:e0156045.

35. Zhou Q, Anderson C, Zhang H, Li X, Inglis F, Jayagopal A, et al. Repression of choroidal neovascularization through actin cytoskeleton pathways by microRNA-24. Mol Ther. 2014:22:378-89.

36. Seo YH, Jo YN, Oh YJ, Park S. Nano-mechanical reinforcement in drugresistant ovarian cancer cells. Biol Pharm Bull. 2015:38:389-95.

37. Yan J, Li F, Ingram DA, Quilliam LA. Rapla is a key regulator of fibroblast growth factor 2-induced angiogenesis and together with Rap1b controls human endothelial cell functions. Mol Cell Biol. 2008;28: 5803-10.

38. Giancotti FG, Ruoslahti E. Integrin signaling. Science. 1999;285:1028-33.

39. Alberts $B$, Johnson A, Lewis J, Raff $M$, Roberts $K$, Walter P. Integrins. In: Molecular biology of the cell. 4th ed; 2002. Garland Sci.

40. Dohn MR, Kooker CG, Bastarache L, Jessen T, Rinaldi C, Varney S, Mazalouskas MD, Pan H, Oliver KH, Edwards DR, Sutcliffe JS. The gain-offunction integrin $\beta 3$ Pro33 variant alters the serotonin system in the mouse brain. J Neurosci. 2017;37(46):11271-84.

41. Liao Z, Kasirer-Friede A, Shattil SJ. Optogenetic interrogation of integrin aVB3 function in endothelial cells. J Cell Sci. 2017;130(20):3532-41.

42. Mehmood $K$, Zhang $H$, Jiang $X$, Yao W, Tong $X$, lqbal MK, et al. Ligustrazine recovers thiram-induced tibial dyschondroplasia in chickens: involvement of new molecules modulating integrin beta 3. Ecotoxicol Environ Saf. 2019;168: 205-11.

43. Lowdell MW, Craston R, Samuel D, Wood ME, O'neill E, Saha V, et al. Evidence that continued remission in patients treated for acute leukaemia is dependent upon autologous natural killer cells. Br J Haematol. 2002;117: $821-7$.

44. Laurenzana I, Caivano A, Trino S, De Luca L, La Rocca F, Simeon V, et al. A Pyrazolo [3, 4-d] pyrimidine compound inhibits Fyn phosphorylation and induces apoptosis in natural killer cell leukemia. Oncotarget. 2016;7:65171.

45. Katzav S, Martin-Zanca D, Barbacid M, Hedge AM, Isfort R, Ihle JN. The trk oncogene abrogates growth factor requirements and transforms hematopoietic cells. Oncogene. 1989;4:1129-35.

46. Liu X, Qu CK. Protein tyrosine phosphatase SHP-2 (PTPN11) in hematopoiesis and leukemogenesis. J Signal Transduct. 2011;2011:195239.

47. Paul S, Lal G. The molecular mechanism of natural killer cells function and its importance in Cancer immunotherapy. Front Immunol. 2017;8:1124.

48. Zhao S, Sedwick D, Wang Z. Genetic alterations of protein tyrosine phosphatases in human cancers. Oncogene. 2015;34:3885.

49. Zanotti S, Canalis E. Notch signaling and the skeleton. Endocr Rev. 2016;37: 223-53.

50. Crowe R, Zikherman J, Niswander L. Delta-1 negatively regulates the transition from prehypertrophic to hypertrophic chondrocytes during cartilage formation. Development. 1999;126:987-98.

51. Liebler SS, Feldner A, Adam MG, Korff T, Augustin HG, Fischer A. No evidence for a functional role of bi-directional Notch signaling during angiogenesis. PLoS One. 2012;7:e53074. 
52. McElhinny AS, Li JL, Wu L. Mastermind-like transcriptional co-activators: emerging roles in regulating cross talk among multiple signaling pathways. Oncogene. 2008;27:5138-47.

53. Cunningham TJ, Duester G. Mechanisms of retinoic acid signalling and its roles in organ and limb development. Nat Rev Mol Cell Biol. 2015;16:11023.

54. Barish GD, Yu RT, Karunasiri MS, Becerra D, Kim J, Tseng TW, et al. The Bcl6SMRT/NCoR cistrome represses inflammation to attenuate atherosclerosis. Cell Metab. 2012;15:554-62.

55. Wang C, Niu S, Jahejo A, Jia F, Li Z, Zhang N, et al. Identification of apoptosis-related genes in erythrocytes of broiler chickens and their response to thiram-induced tibial dyschondroplasia and recombinant glutathione-S-transferase A3 protein. Res Vet Sci. 2018;120:11-6.

56. Rath N, Huff W, Balog J, Huff G. Comparative efficacy of different dithiocarbamates to induce tibial dyschondroplasia in poultry. Poult Sci. 2004;83:266-74

57. Tian W, Zhang W, Li J, Bi D, Guo D, Pan S, et al. Identification of differentially expressed genes in the growth plate of broiler chickens with thiraminduced tibial dyschondroplasia. Avian Pathol. 2009;38:161-6.

58. Jafari S, Morteza S, Hunger R. IHC optical density score: a new practical method for quantitative immunohistochemistry image analysis. Appl Immunohistochem Mol Morphol. 2017;25:e12-3.

59. Kim D, Pertea G, Trapnell C, Pimentel H, Kelley R, Salzberg SL. TopHat2: accurate alignment of transcriptomes in the presence of insertions, deletions and gene fusions. Genome Biol. 2013;14:R36.

60. Trapnell C, Williams BA, Pertea G, Mortazavi A, Kwan G, Van Baren MJ, et al. Transcript assembly and quantification by RNA-Seq reveals unannotated transcripts and isoform switching during cell differentiation. Nature biotech. 2010;28:511

61. Anders S, Huber W. Differential expression analysis for sequence count data. Genome Biol. 2010;11:R106.

62. Conesa A, Götz S, García-Gómez JM, Terol J, Talón M, Robles M. Blast2GO: a universal tool for annotation, visualization and analysis in functional genomics research. Bioinformatics. 2005;21(18):3674-6.

63. Tatusov RL, Galperin MY, Natale DA, Koonin EV. The COG database: a tool for genome-scale analysis of protein functions and evolution. Nucleic Acids Res. 2000;28(1):33-6.

\section{Publisher's Note}

Springer Nature remains neutral with regard to jurisdictional claims in published maps and institutional affiliations.

Ready to submit your research? Choose BMC and benefit from:

- fast, convenient online submission

- thorough peer review by experienced researchers in your field

- rapid publication on acceptance

- support for research data, including large and complex data types

- gold Open Access which fosters wider collaboration and increased citations

- maximum visibility for your research: over $100 \mathrm{M}$ website views per year

At BMC, research is always in progress.

Learn more biomedcentral.com/submissions 